\title{
Assessment of satisfaction with different dry powder inhalation devices in Greek patients with COPD and asthma: the ANASA study
}

This article was published in the following Dove Press journal:

International Journal of COPD

5 August 2016

Number of times this article has been viewed

\section{Eleftherios Zervas \\ Konstantinos Samitas Mina Gaga}

7th Respiratory Department and Asthma Center, Athens Chest Hospital "Sotiria", Athens, Greece
Correspondence: Eleftherios Zervas 7th Respiratory Department and Asthma Center, Athens Chest Hospital "Sotiria", I 52 Mesogion Avenue, Athens II527, Greece Tel +302107781720 Fax +30210778 1911 Email lefzervas@yahoo.gr
Background: Poor adherence to inhaled therapy is common in patients with asthma and COPD. An inhaler selection based on patients' preference could be beneficial to adherence and treatment effectiveness. Properly designed questionnaires can assess patients' satisfaction with their medication devices. The aim of this study was to estimate, using the Feeling of Satisfaction with Inhaler (FSI-10) questionnaire, the ease of use and satisfaction of patients regarding three different marketed dry powder inhalers (DPIs): Diskus ${ }^{\circledR}(\mathrm{DK})$, Elpenhaler $^{\circledR}(\mathrm{EH})$, and Turbuhaler $^{\circledR}$ (TH). The FSI-10 is a self-completed questionnaire to assess patients' opinions regarding ease of use, portability, and usability of devices, irrespective of the drug used.

Patients and methods: We performed a 4-week, open, noninterventional, multicenter, parallel clinical study in 560 asthmatic and 561 COPD patients. During the first visit, patients were classified into three groups according to the DPI they were already using. Patients were regularly receiving their treatments (Seretide DK, Rolenium EH, and Symbicort TH) and agreed to complete the FSI-10 questionnaire in the second visit.

Results: A total of 517 COPD and 523 asthma patients completed the study. All DPIs tested received satisfactory results, while the EH obtained consistently higher scores in the FSI-10 in both COPD and asthma patients (44.7 and 44.1 vs 41.5 and 43 for TH, 40.8 and 41.4 for DK, $P<0.001$ and $P<0.01$, respectively). TH was rated better than DK by asthma patients. Patients suffering with severe COPD tended to express higher feeling of satisfaction than those with moderate or mild disease, irrespective of the device used.

Conclusion: All DPIs tested were highly acceptable by asthma and COPD patients of different ages; nevertheless, EH received significantly higher ratings in most of the questionnaire domains. COPD patients in advanced stages of the disease generally expressed higher level of satisfaction with their devices.

Keywords: asthma, COPD, dry powder inhaler, patient satisfaction, FSI-10 questionnaire

\section{Introduction}

Asthma and COPD are chronic obstructive lung diseases that affect millions of patients and add a huge burden to health care systems worldwide. ${ }^{1-3}$ Based on current treatment guidelines, both diseases are treated with maintenance medications delivered daily by inhaler devices (usually a combination of bronchodilators and inhaled corticosteroids). ${ }^{4,5}$ However, it is common for patients under prolonged treatment to have poor adherence to medication. ${ }^{6,7}$ Patients' adherence to treatment can be influenced by their overall state of being, as well as by the frequency of dosing, their expectations regarding treatment of their disease and its outcomes, and to a great extent by the quality and ease of use of the device. 
A wide choice of inhaler devices with different drug combinations exist nowadays that offer excellent therapeutic results, when used efficiently. ${ }^{8}$ However, there is still space for improvement regarding device-related attributes that are considered important to the patients, such as ease of use, size, and portability. It has been suggested that allowing the patient to choose the inhalation device might help to increase acceptance of therapy and adherence. ${ }^{9-12}$ The idea is that involving the patient in the decision-making process will result in enhancing patient satisfaction with the inhaler device, which in turn will lead to increased adherence, better clinical outcomes, and reduced health care expenditures. ${ }^{10}$ Recent evidence-based guidelines for device selection and outcomes of aerosol therapy have pointed out the importance of tailoring the device to the patient. ${ }^{8}$ The Global Initiative for Asthma (GINA) guidelines recognize that individual patient preference, convenience, and ease of use may influence not only the efficiency of drug delivery but also patients' adherence to treatment and long-term control. Moreover, the GINA guidelines suggest that patients should see several inhaler devices and participate in the decision over which is best for them. ${ }^{4}$

Patient satisfaction is by no means a new concept and its clinical significance became evident a long time ago. ${ }^{13}$ In this context, patient satisfaction can be defined as the extent to which the inhaler fulfills the patient requirements, in terms of his/her expectations of the device features. ${ }^{11}$ There is evidence supporting the association between inhaler satisfaction and patient adherence, as well as improved clinical outcome. Patients who use their preferred inhaler device may obtain a greater degree of satisfaction with therapy, while lack of satisfaction with treatment is associated with a worst disease course and poorer disease control in patients with asthma. ${ }^{14,15}$ Moreover, both asthma and COPD patients are more likely to be compliant and experience better outcomes when they are satisfied with their inhalers. ${ }^{10,11}$

This study was an open, noninterventional, multicenter, parallel, 4-week clinical trial designed to compare patient satisfaction with three different commercially available dry powder inhalers (DPIs) delivering inhaled corticosteroid/ long-acting $\beta 2$-agonist fixed combinations: Seretide Diskus ${ }^{\circledR}$ (DK), a multidose blister DPI (GlaxoSmithKline plc, London, UK); Rolenium Elpenhaler ${ }^{\circledR}$ (EH), a single-dose blister DPI (Elpen Pharmaceuticals Co. Inc., Pikermi, Greece); and Symbicort Turbuhaler ${ }^{\circledR}(\mathrm{TH})$, a multidose reservoir DPI (AstraZeneca plc, London, UK). This study was conducted in a real-world clinical setting in a large pool of patients with both asthma and COPD already treated with any of the three studied DPIs for a rather long period of time, using a recently validated Greek version of the FSI-10 questionnaire. ${ }^{16}$

\section{Patients and methods Study design and population}

This study was a prospective, observational, 4-week, open, noninterventional, multicenter, parallel clinical study performed in 79 private practice and hospital centers across Greece between January and September 2011. The primary outcome of the study was patient satisfaction with the inhaled device used and the secondary outcomes were treatment efficacy (according to lung function measurements) and safety.

A total of 1,121 patients (561 COPD and 560 asthma patients) were recruited in the study. Demographic characteristics and distribution of patients with asthma and COPD stratified by disease severity and inhaler device are presented in Table 1. Male or female patients of $>18$ years of age with a history of either COPD or asthma for at least 6 months and under fixed combination therapy with inhaled budesonide/ formoterol or fluticasone/salmeterol were included in the study. The study's primary outcome was to assess patients' satisfaction with the DPI devices they were already familiarized within a real-world clinical setting. Therefore, patients had to have achieved mastery in any of the three studied DPIs for at least 2 months before enrollment, in order to be enrolled in the study. Disease severity for asthma and COPD was defined according to current GINA and Global Initiative for Chronic Obstructive Lung Disease guidelines, respectively. 4,5 All patients were informed regarding the study procedures and objectives and signed an informed consent form before study enrollment. The study was approved by the Athens Chest Hospital Ethics Committee as well as the corresponding institutional ethics committees and was registered with ClinicalTrials.gov (NCT01475045).

During the first visit (day 0), patients were informed about the study and a written consent was obtained. Demographics and medical history were obtained and patients were categorized in one of the three available groups, depending on the inhaler device they were using. The attending physician assessed directly the patients' inhalation technique, and in cases of critical errors, instructions for proper use were given. During the second visit (week 4), patients were interviewed regarding possible exacerbations about the use of rescue medication or the addition of oral corticosteroids, as well as the occurrence of any adverse events. Patients were instructed on how to answer the questions of the FSI-10 questionnaire and asked that they do so honestly on their own. Spirometry was performed at both visit 0 and visit 1 . 
Table I Characteristics of all patients with asthma and COPD and distribution according to disease severity and inhaler device

\begin{tabular}{|c|c|c|c|c|c|}
\hline & Diskus $^{\circledR}$ & Elpenhaler $^{\circledR}$ & Turbuhaler $^{\circledR}$ & Total & P-value \\
\hline \multicolumn{6}{|l|}{ Asthma } \\
\hline Number of patients recruited & 173 & 163 & 224 & 560 & 0.09 \\
\hline Number of patients lost in follow-up & 10 & II & 16 & 37 & 0.18 \\
\hline Number of patients who completed the study & 163 & 152 & 208 & 523 & 0.07 \\
\hline Sex, $n$ & & & & & 0.53 \\
\hline Male & 67 & 51 & 73 & 191 & \\
\hline Female & 98 & 101 & 135 & 332 & \\
\hline Age (years) & $51.6(15.6)$ & $49.9(16.3)$ & $49.5(16.2)$ & $50.3(16.1)$ & 0.42 \\
\hline Disease duration (years) & $23.7(15)$ & $22.9(16.5)$ & $21.5(14)$ & $22.5(15.1)$ & 0.23 \\
\hline Time in DPI (months) & $11.9(9.8)$ & $12.6(10.2)$ & $12.3(10.1)$ & $12.3(10.3)$ & 0.81 \\
\hline Height (cm) & I66.I (9.2) & I67.I (10.9) & I 66.5 (8.9) & $166.6(9.6)$ & 0.67 \\
\hline $\mathrm{BMI}\left(\mathrm{kg} / \mathrm{m}^{2}\right)$ & $28.6(5.3)$ & $27.9(6.9)$ & $27.3(5.9)$ & $27.9(5.9)$ & 0.10 \\
\hline Smoking status (\%) & & & & & 0.54 \\
\hline Current smokers & 16.4 & 20.3 & 13.7 & 16.4 & \\
\hline Ex-smokers & 19.9 & 20.3 & 22.9 & 21.2 & \\
\hline Never smokers & 63.7 & 59.5 & 63.4 & 62.4 & \\
\hline Disease severity, $\mathrm{n}$ & & & & & 0.62 \\
\hline Mild & 43 & 47 & 60 & 150 & \\
\hline Moderate & 97 & 86 & 126 & 308 & \\
\hline Severe & 23 & 20 & 22 & 65 & \\
\hline $\mathrm{FEV}_{1}(\mathrm{It})$ & $2.45(0.98)$ & $2.39(0.89)$ & $2.44(0.85)$ & $2.43(0.9)$ & 0.78 \\
\hline FEV ( $\%$ of predicted) & $84.3(20.9)$ & $82.2(19.5)$ & $84.3(19.5)$ & $83.7(20)$ & 0.58 \\
\hline $\mathrm{FEV} / \mathrm{FVC}$ & $76.8(15.3)$ & $80.7(10.4)$ & $77.9(13.3)$ & $79.0(13.3)$ & 0.12 \\
\hline \multicolumn{6}{|l|}{ COPD } \\
\hline Number of patients recruited & 201 & 208 & 152 & 561 & 0.07 \\
\hline Number of patients lost in follow-up & 16 & 16 & 12 & 44 & 0.14 \\
\hline Number of patients who completed the study & 185 & 192 & 140 & 517 & 0.09 \\
\hline Sex, $n$ & & & & & 0.10 \\
\hline Male & 136 & 144 & 117 & 397 & \\
\hline Female & 49 & 48 & 23 & 120 & \\
\hline Age (years) & $66.5(9.0)$ & $66(10.8)$ & $65.9(10.7)$ & $66.1(10.2)$ & 0.85 \\
\hline Disease duration (years) & $7.7(5.5)$ & $7.9(6.5)$ & $7.5(5.4)$ & $7.6(5.8)$ & 0.73 \\
\hline Time in DPI (months) & $10.9(8.8)$ & II.6 (9.2) & II.4 (8.I) & II.3 (8.8) & 0.51 \\
\hline Height $(\mathrm{cm})$ & $167.6(8.4)$ & I68.I (8.4) & $168.8(8.2)$ & I68.I (8.4) & 0.43 \\
\hline BMI $\left(k g / m^{2}\right)$ & $28.4(5)$ & $28.4(5.2)$ & $28.1(6.1)$ & $28.3(5.4)$ & 0.79 \\
\hline Smoking status (\%) & & & & & 0.83 \\
\hline Current smokers & 35.8 & 34.5 & 33.6 & 34.7 & \\
\hline Ex-smokers & 54.7 & 58.9 & 58.7 & 57.4 & \\
\hline Never smokers & 9.5 & 6.6 & 7.7 & 7.9 & \\
\hline Disease severity, $n$ & & & & & 0.74 \\
\hline Stage I & 30 & 31 & 21 & 82 & \\
\hline Stage II & 82 & 100 & 67 & 249 & \\
\hline Stage III & 61 & 52 & 40 & 153 & \\
\hline Stage IV & 12 & 9 & 12 & 33 & \\
\hline $\mathrm{FEV}_{1}(\mathrm{It})$ & $\mathrm{I} .64(0.70)$ & $\mathrm{I} .72(0.65)$ & $\mathrm{I} .65(0.67)$ & $1.67(0.68)$ & 0.42 \\
\hline FEV (\% of predicted) & $61.2(12.3)$ & $64.1(11.5)$ & $59.6(1 \mathrm{I} . \mathrm{I})$ & 61.8 (II.7) & 0.14 \\
\hline $\mathrm{FEV}_{1} / \mathrm{FVC}$ & $59.1(6.8)$ & $58.6(4.8)$ & $54.8(6.7)$ & $57.2(6.1)$ & 0.09 \\
\hline
\end{tabular}

Note: Data are presented as mean (SD) unless otherwise specified.

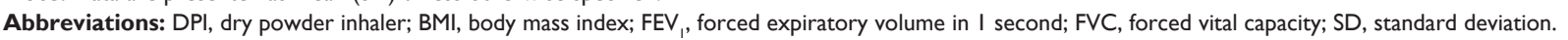

\section{FSI-I 0 questionnaire}

Patient satisfaction with their corresponding DPI was evaluated by means of FSI-10 questionnaire, which was adapted in linguistic and cultural terms for Greek patients. ${ }^{16}$ The FSI-10 is a self-completed questionnaire designed to assess patients' opinion regarding the satisfaction and usability of the inhalers, irrespective of the medication or formulation used. ${ }^{17}$ It consists of ten questions, each with five possible responses on a five-point Likert scale (very, fairly, somewhat, not very, and hardly at all) scored from 5 to 1 , respectively (Supplementary material). The total score can range between 10 and 50, with higher scores corresponding 
to higher level of feeling of patient satisfaction from the inhaler.

\section{Statistical analysis}

Data were expressed as mean (SD) or percentages, unless otherwise specified. Normality was assessed using D'AgostinoPearson omnibus normality tests. To establish the homogeneity index of the FSI-10 questionnaire, the Pearson's correlation coefficient regarding the scores on each question and the total score was calculated to assess the relationship between questions. Reliability was assessed in terms of internal consistency according to the Cronbach's $\alpha$, considering that values $>0.8$ reflected good internal consistency. One-way analysis of variance followed by Bonferroni post hoc correction or the Pearson chi-square test with appropriate post hoc analysis were used to compare FSI-10 total scores and individual question frequencies between the tested inhaler devices. Two-way analysis of variance was used for subgroup analysis with respect to age and disease severity. Statistical software packages were used for data analysis and graph preparation (SPSS Version 20; SPSS Inc., Chicago, IL, USA, and Prism Version 5; GraphPad Software, Inc., La Jolla, CA, USA, respectively). A $P$-value of 0.05 was considered statistically significant.

\section{Results}

\section{Patient characteristics}

A total of 1,121 patients (561 COPD and 560 asthma patients) were initially recruited in the study. Eighty-two patients (38 asthma and 44 COPD patients) were lost to follow-up (Table 1). The final patient groups consisted of 523 (332 women and 191 men) asthmatic patients and 517 (120 women and 397 men) COPD patients, with a mean (SD) age of $50.3( \pm 16.1)$ years and $66.1( \pm 10.2)$ years, respectively. All patients used one of the three studied DPIs for at least
2 months before enrollment, with a mean $( \pm \mathrm{SD})$ time of using the corresponding device of $12.3( \pm 10.3)$ months and 11.3 $( \pm 8.8)$ months for asthma and COPD patients, respectively. There were no differences with respect to patient characteristics, DPI use, or disease severity between asthma and COPD groups (Table 1).

\section{FSI- I0 questionnaire validation data}

The Greek version of the FSI-10 was easily understood and completed by the participants. None of the ten items on the questionnaire were left without response. The FSI-10 displayed adequate homogeneity with no redundancy, as no correlation $>0.8$ was found between the questions (Table 2 ). Cronbach's test for the questionnaire as a whole showed very good internal consistency (Cronbach's $\alpha=0.898$ ). Lower $\alpha$ values $(0.879-0.890)$ were calculated, if any of the items was consecutively deleted.

\section{FSI- I 0 questionnaire scores}

Consistent and satisfactory results were obtained with all DPIs tested; however, certain statistically significant differences in the ratings between the devices were observed in both asthma and COPD patients. Specifically, regarding patients with asthma, the total score (mean [SD]) on the FSI-10 for each of the inhalers was 41.4 (6.1) for the DK, 44.1 (5.3) for the EH, and 43 (5.3) for the TH (Figure 1A). The $\mathrm{EH}$ was rated best in seven of the ten questions (questions 1 , 3-7, and 10; Table 3). It also had significantly higher mean total score compared to DK ( $P<0.001$; Figure 1A), but not to $\mathrm{TH}(P=0.16$; Figure $1 \mathrm{~A})$.

TH was rated first in questions 7 and 8 of the FSI-10 questionnaire (Table 3 ) and presented a significantly higher mean total score compared to DK ( $P<0.05$; Figure 1A). DK was rated first only in question 2 , but with no statistical difference from the other two devices (Table 3). No significant

Table 2 The FSI-I0 interitem correlation matrix

\begin{tabular}{|c|c|c|c|c|c|c|c|c|c|c|}
\hline & QI & Q2 & Q3 & Q4 & Q5 & Q6 & Q7 & Q8 & Q9 & Q10 \\
\hline QI & I & 0.648 & 0.640 & 0.403 & 0.373 & 0.400 & 0.414 & $0.28 I$ & 0.458 & 0.550 \\
\hline Q2 & 0.648 & 1 & 0.628 & 0.403 & 0.393 & 0.305 & $0.4 \mathrm{II}$ & 0.301 & 0.335 & 0.503 \\
\hline Q3 & 0.640 & 0.628 & $I$ & 0.473 & 0.499 & 0.470 & 0.472 & 0.362 & 0.513 & 0.615 \\
\hline Q4 & 0.403 & 0.403 & 0.473 & 1 & 0.478 & 0.474 & 0.447 & 0.370 & 0.443 & 0.513 \\
\hline Q5 & 0.373 & 0.393 & 0.499 & 0.478 & I & 0.498 & 0.597 & 0.516 & 0.452 & 0.582 \\
\hline Q6 & 0.400 & 0.305 & 0.470 & 0.474 & 0.498 & I & 0.507 & 0.405 & 0.529 & 0.572 \\
\hline Q7 & 0.414 & $0.4 I I$ & 0.472 & 0.447 & 0.597 & 0.507 & I & 0.634 & 0.442 & 0.592 \\
\hline Q8 & 0.281 & 0.301 & 0.362 & 0.370 & 0.516 & 0.405 & 0.634 & I & 0.322 & 0.478 \\
\hline Q9 & 0.458 & 0.335 & 0.513 & 0.443 & 0.452 & 0.529 & 0.442 & 0.322 & I & 0.666 \\
\hline Q10 & 0.550 & 0.503 & 0.615 & 0.513 & 0.582 & 0.572 & 0.592 & 0.478 & 0.666 & I \\
\hline
\end{tabular}

Abbreviations: FSI-10, Feeling of Satisfaction with Inhaler; Q, question. 

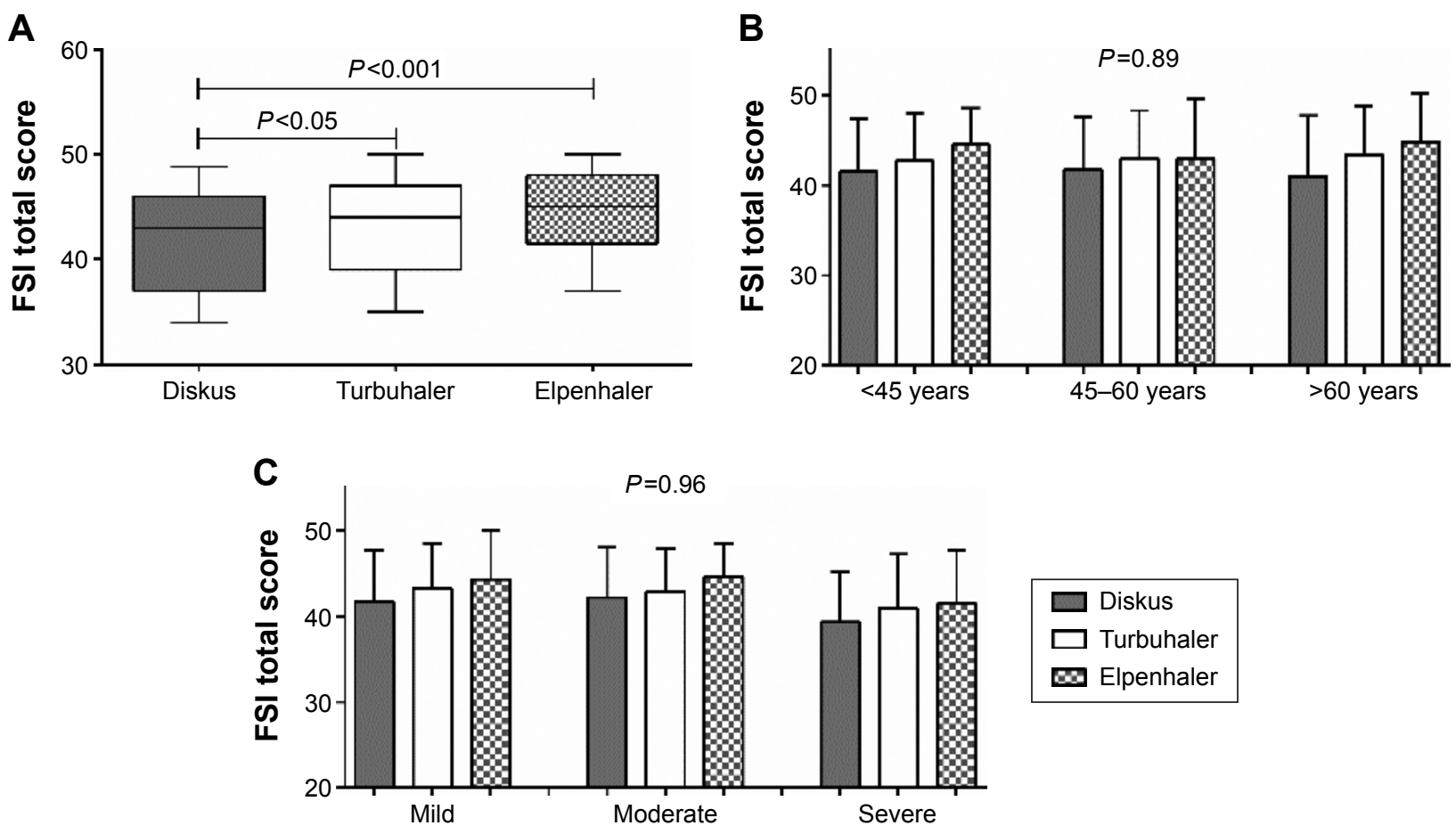

Figure I Estimated differences in the mean total score of the FSI- 10 questionnaire in 523 asthma patients between the examined inhalers (A), according to the age category of the patients (B), and the asthma severity stage (C) for every inhaler studied.

Abbreviations: FSI-10, Feeling of Satisfaction with Inhaler; FSI, Feeling of Satisfaction.

differences were observed regarding age $(P=0.89$; Figure 1B) or disease severity $(P=0.96$; Figure $1 \mathrm{C})$, in any of the tested devices.

With respect to COPD patients, the total score (mean [SD]) on the FSI-10 for each of the inhalers was 40.8 (6.9) for the DK, 44.7 (4.4) for the EH, and 41.5 (5.8) for the $\mathrm{TH}$ (Figure 2A). EH was also rated first in eight of the ten questions (questions 1, 3-7, and 9-10; Table 3) having also a significantly higher mean total score compared to DK and TH (both $P<0.001$; Figure $2 \mathrm{~A}$ ). TH was rated first only in question 8 of the FSI-10 questionnaire (Table 3), showing no statistically significant difference in mean total score compared to DK ( $P=0.86$; Figure $2 \mathrm{~A}$ ). DK was rated first only in question 2 , but with no statistical difference compared to the other two devices (Table 3 ). No significant differences in scores were observed regarding age ( $P=0.12$; Figure $2 \mathrm{~B}$ ), in any of the tested devices. It should also be noted that patients suffering with severe COPD tended to express a higher feeling of satisfaction with their devices compared to those with mild or moderate disease $(P<0.05$; Figure $2 \mathrm{C})$.

\section{Efficacy and safety}

A total of 39 patients (13 with asthma and 26 with COPD) experienced an exacerbation during the study. No differences in exacerbation rates were observed between the three studied groups in either asthma or COPD (DK 3\% and 4.2\%, EH $1.3 \%$ and $5 \%$, and $\mathrm{TH} 2.9 \%$ and $5.6 \%$, in asthma and COPD patients, respectively; $P=0.76$ ).

No differences were observed with respect to forced expiratory volume in 1 second measurements during the 1-month study period between all inhaler groups, in both asthma and COPD patients. For the specific inhaled corticosteroid/longacting $\beta 2$-agonist fixed combinations treatments, the mean (SD) difference in forced expiratory volume in 1 second between visits 1 and 2 was $0.08 \mathrm{~L}(0.37)$ and $0.16 \mathrm{~L}(0.39)$ for DK, $0.18 \mathrm{~L}(0.50)$ and $0.12 \mathrm{~L}(0.37)$ for $\mathrm{TH}$, and $0.20 \mathrm{~L}$ $(0.49)$ and $0.18 \mathrm{~L}(0.45)$ for $\mathrm{EH}$, respectively, for the asthma and COPD groups ( $P=0.08$ and $P=0.37$, respectively).

\section{Discussion}

In this study, we investigated the ease of use and satisfaction of patients with asthma and COPD in a cohort of Greek patients regarding three different marketed DPI devices, which they had already been using. The assessment of patient satisfaction was performed by a specifically designed self-completed questionnaire, the FSI-10, which was easily understood and completed by the participants. All DPIs tested received satisfactory results; however, EH consistently received higher FSI-10 scores in both COPD and asthma patients. Moreover, severe COPD patients tended to express 


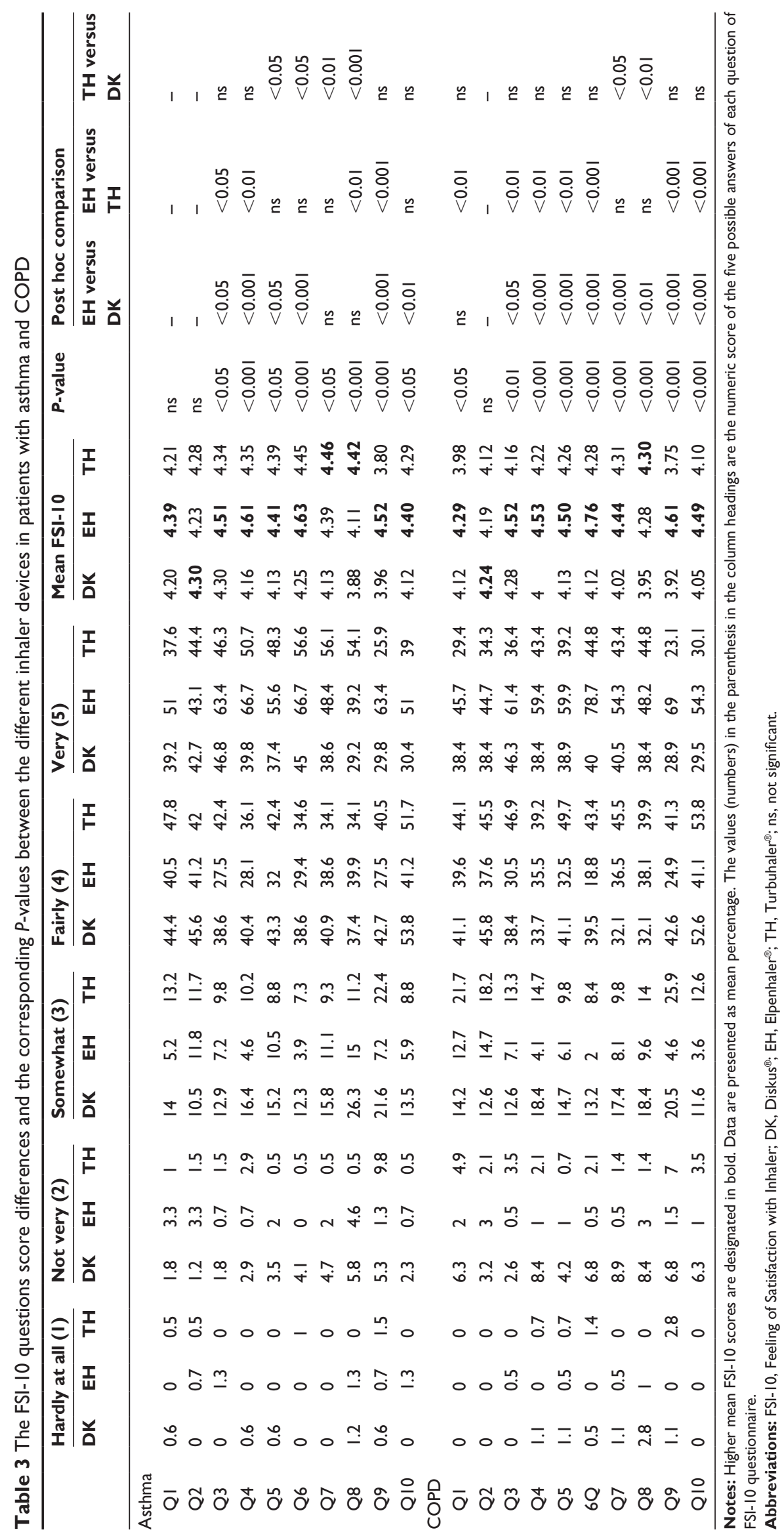



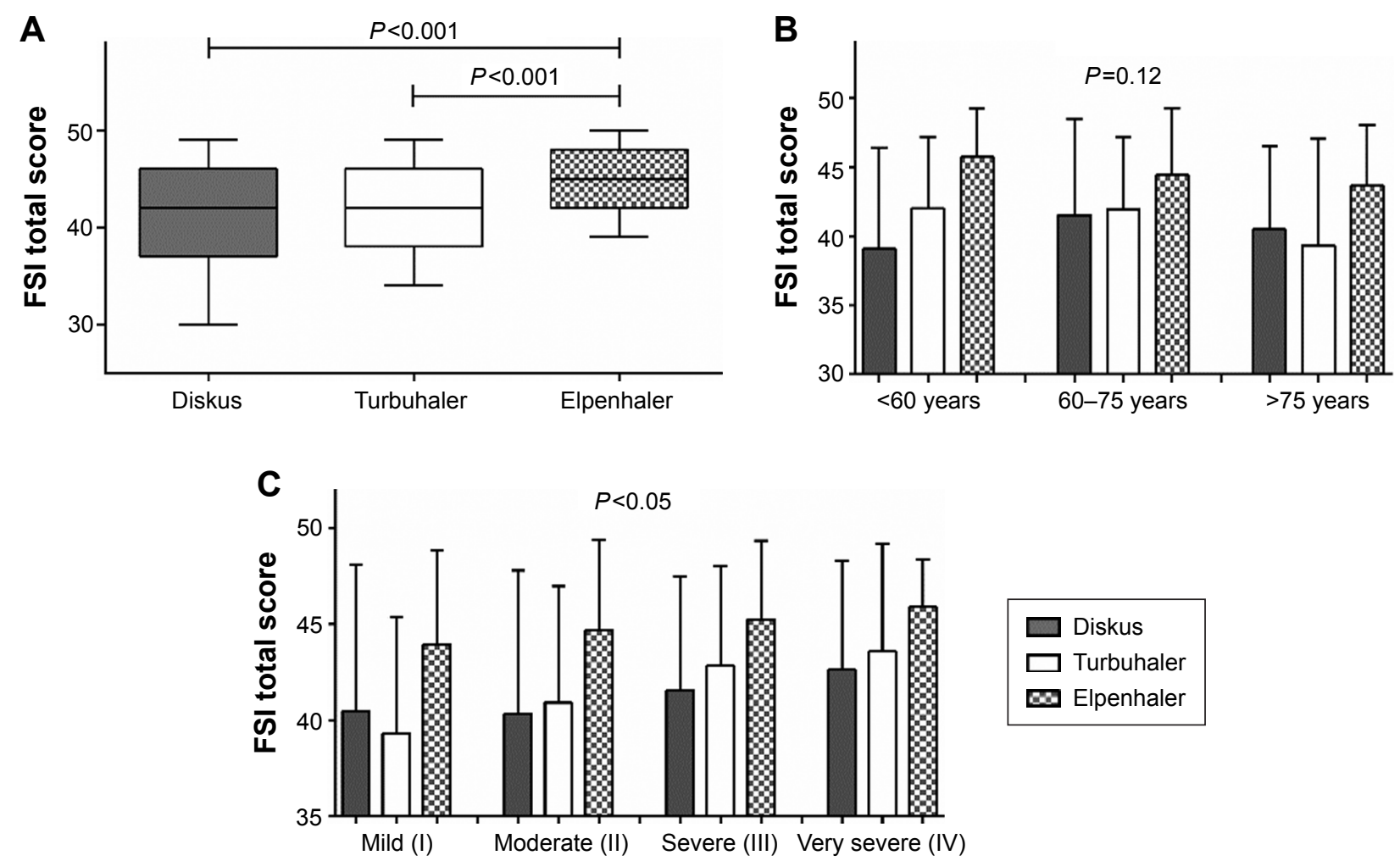

Figure 2 Estimated differences in the mean total score of the FSI- 10 questionnaire in 5 I 7 COPD patients, between the examined inhalers (A), according to the age category of the patients (B), and the COPD severity stage (C) for every inhaler studied.

Abbreviations: FSI-10, Feeling of Satisfaction with Inhaler; FSI, Feeling of Satisfaction.

higher feeling of satisfaction than those with moderate or mild disease, irrespective of the device used. To the best of our knowledge, no other study has ever examined in a standardized fashion patient satisfaction with their inhaler devices in the Greek population.

Several types of devices for delivery of inhaled drugs are currently available; however, no inhaler currently fits the profile of the ideal inhaler device. ${ }^{18,19}$ Many inhalerrelated factors, such as size, portability, and ease of use can affect inhaler preference and patient satisfaction. ${ }^{11,19-21}$ The issue of patient satisfaction with their inhaler devices has been increasingly addressed over the last few years, mostly because of the evidence linking inhaler satisfaction with patient adherence and improved clinical outcomes. ${ }^{10,22-27}$ Patients using their preferred inhaler are more likely to obtain a greater degree of satisfaction with therapy. This is of outmost importance as lack of satisfaction with treatment is associated with low compliance and, consequently, poor control and worse disease course. . $^{10,11,14}$

There are no standardized questionnaires assessing patient satisfaction with inhaler devices available for use in the Greek language other than the FSI-10, which was only recently translated and validated for use in Greece. ${ }^{16}$ Other types of instruments used in similar inhaler satisfaction studies range from simple preference questions to psychometrically developed and validated questionnaires. ${ }^{28,29}$ Response scales of these instruments range from open-ended questions, through unclear response scales, to visual analog and Likert scales. ${ }^{30,31}$ Comparison between the visual analog scale and the Likert measuring scale used in the FSI-10 questionnaire showed the latter to have better predictive performance. ${ }^{30}$ The FSI-10 questionnaire quantifies the various aspects that are important to patients who use inhaler devices, such as ease of use and portability.

The FSI-10 questionnaire has been used in order to compare satisfaction and preferences in 112 stable asthmatic patients regarding three different devices TH, Accuhaler ${ }^{\circledR}$ (ie, DK), and Novolizer ${ }^{\circledR}$ (NV), a multidose reservoir DPI (Meda Pharmaceuticals, Somerset, NJ, USA), in a multicenter, prospective, observational study in Spain. ${ }^{17}$ In this study, the FSI-10 was found to be a useful instrument for assessing the degree of satisfaction of adult and pediatric asthmatic patients. The highest scoring and most often preferred inhaler was the NV, while, in accordance to the findings of this study among the Greek patients, the Spanish asthma patients reported higher score for TH compared 
to DK. This preference was, partly, attributed by the authors to TH having been the device that was commonly used by the patients prior to the study, even though an overall younger age effect was evident in favor of NV. ${ }^{17}$

The FSI-10 questionnaire has also been used to evaluate patient satisfaction in Turkey, in 442 patients with COPD, in real-life clinical practice. Data concerning the ease of use, the portability, and the usability of the device were collected on the basis of a single cross-sectional patient visit, for COPD patients who had already been on budesonide/formoterol TH therapy, for 3 months at least, prior to study enrollment. The results revealed that the majority of patients were able to use $\mathrm{TH}$, whereas older age was associated with higher rate of errors in inhalation maneuvers, while the majority of patients were satisfied with the overall use of the device. ${ }^{25}$

To the best of our knowledge, this study is the first one performed in a real-life clinical settings, evaluating patient satisfaction regarding three different widely used DPIs, in a large cohort of both COPD and asthma patients. The validation data from our study indicate that the FSI-10 questionnaire is comprehensible, easy to use, and has satisfactory measurement properties. It shows a good association between questions and a positive contribution of the score of each question to the total score. Moreover, the questionnaire as a whole demonstrates very good internal consistency and no redundancies. However, no data are available regarding the sensitivity or the minimum clinically significant difference of the FSI-10, which accounts for the interim and exploratory nature of the interpretation of its results. It is a judgment that a well-designed and conducted study, showing prospectively defined important statistical significance, has an effect size that is clinically meaningful, in the context of the clinical relevance of the end point used in a study. Nonetheless, the statistically significant differences we observed, regarding the consistently higher FSI-10 scores for the EH in both COPD and asthmatic patients, could, possibly, be important in the clinical setting.

In a recent study, DK and TH were compared to Nexthaler ${ }^{\circledR}$, a multidose reservoir DPI (Chiesi, Parma, Italy), in terms of usability and asthma patient satisfaction. ${ }^{23}$ Similar to the results obtained in our study concerning asthma patients who already use their devices, TH presented the worst score corresponding to verification of dose delivery, in 66 DPI naive adult patients compared to the other devices, including DK. ${ }^{23}$ However, TH was superior to DK in its easiness to keep the inhaler clean and in good working condition, its efficacy to continue normal activities with the use of the inhaler, its easiness in terms of size and weight, and its easiness to be carried, only in patients with asthma.
In contrast, DK was found to be superior compared to $\mathrm{TH}$ in another study of 169 powder-naive patients with asthma or COPD, in terms of the presence of a dose counter, ease of learning to use, design, attached cover, and comfortable mouthpiece. ${ }^{26}$ Similar to the findings of a comparative study in device-naive COPD patients ${ }^{27}$ and our study as well, TH was favored over DK regarding factors related to size and ease of holding.

$\mathrm{EH}$ is a newly developed single-dose DPI, designed to administer fixed combinations of fluticasone propionate/ salmeterol and budesonide/formoterol, similarly to DK and $\mathrm{TH}$, respectively. ${ }^{32,33}$ In a recent cross-sectional randomized cross-over multicentre study involving DPI-naive patients with COPD and asthma, van der Palen et $\mathrm{al}^{22}$ compared DK to $\mathrm{EH}$ with regard to DPI patient preference and satisfaction, along with inhaler technique critical errors. Contrary to our findings, their study concluded that patients were more satisfied, in general, with DK and that more patients preferred DK over EH. ${ }^{22}$

Various differences concerning the design of both studies could be accounted for this discrepancy. Initially, our study intended to assess neither inhalation errors nor patient preference; hence, it was not designed to be a cross-over study. Second, patients in our study were already properly instructed and familiar with their inhalers. As van der Palen et al ${ }^{22}$ have also indicated, their findings referred to the patients' opinion at a first glance and their limited experience with the devices, as they were instructed only once, on how to use their assigned device. Inhaler satisfaction may shift when patients become more accustomed with one device after more extended use, as was the case in our study. This could also explain why in question 2 of FSI-10 questionnaire (Was it easy to prepare the inhaler for use?), despite significant differences in device preparation steps (DK four and TH five vs EH ten steps), although DK was rated first by both asthma and COPD patients, there was no statistical difference from the other two devices. Moreover, several issues regarding the design and methodology of the study could possibly be further responsible for the differences observed between the conclusions of the two studies. ${ }^{34}$

Our study also revealed some interesting differences between tested DPIs in specific components of the FSI-10 questionnaire. Similar to the findings of other studies in asthma ${ }^{23}$ and COPD, ${ }^{27} \mathrm{TH}$ was favored over DK - and in our study over also $\mathrm{EH}$ - regarding factors related to size and ease of holding, with significant higher scores in questions 7 ("Was using the inhaler easy in terms of size and weight?") and 8 ("Was it easy to carry the inhaler with you?") of the FSI-10. 
On the other hand, one of the major advantages of $\mathrm{EH}$ seemed to be the verification of dose delivery, as $>60 \%$ of both asthma and COPD patients scored 5 (very satisfied) in question 9 of FSI-10 ("After you've used the inhaler, do you have the feeling that you used it correctly?") compared with $<30 \%$ for both DK and TH. Nevertheless, these differences must be interpreted with caution, as they are not derived from a direct comparison of the three DPI inhalers in a cross-sectional designed study and rather reflect patients' general feeling and familiarity with their device.

Previous DPI patient preference and satisfaction clinical studies that involve a variety of devices have also lead to divergent conclusion. ${ }^{9,35}$ Contradictive interpretations of the results may derive from the lack of a robust and widely used instrument for measuring preference and satisfaction and the exclusion of patients with unstable disease or unable to use inhalers, along with the involvement of the pharmaceutical industries in the study design. Indeed, in the vast majority of the studies sponsored by a pharmaceutical industry, with DK and TH featuring prominently, the sponsor's device was widely preferred. ${ }^{9}$

This study presents certain limitations. As already stated, we did not assess patients' preference or inhaler technique, therefore our study was not designed to be a cross-over study, which is important when comparing devices that administer the same drug. ${ }^{9}$ However, we believe that the longitudinal design of our study was essential in addressing the main aim of our study. Another limitation, as with other preference studies, was the fact that patients with unstable disease or those unable to use inhalers correctly were excluded from our study. In addition, the study included patients $>18$ years of age, so further studies to investigate the patient satisfaction in pediatric and adolescent asthma patients could be warranted. Nevertheless, evaluations across patients with asthma and COPD, deriving from diverse ethnic and cultural background, ${ }^{17,25}$ led us to the conclusion that the FSI-10 is a reliable, practical, and responsive instrument for measuring inhalation device satisfaction.

\section{Conclusion}

Inhaler satisfaction is a useful patient-reported outcome, which should be considered in clinical studies assessing inhaler devices in COPD and asthma. Considering patients' preference and satisfaction when choosing an inhaler device could possibly be associated with better adherence and enhanced clinical outcomes. Future research should focus on the effect of patient-reported device preference and degree of satisfaction on adherence, quality of life, disease control, and clinical outcome.

\section{Acknowledgments}

The study was sponsored by Elpen Pharmaceuticals Co. Inc. The authors declare no third party involvement in the study design, data collection, statistical analysis and evaluation, and manuscript preparation and submission.

\section{Disclosure}

EZ has received speaker fees and conference travel grants from pharmaceutical companies, including AstraZeneca, GlaxoSmithKline (GSK), Elpen, Boehringer Ingelheim, Takeda, Novartis, Pfizer, UCB, Chiesi, Menarini, Roche, MSD, and Sherhing-Plough. Also EZ has received payment for consulting and advisory board involvement from AstraZeneca, GSK, Elpen, Novartis, and Menarini. KS has received speaker fees from Novartis and conference travel grants from Novartis, GSK, Elpen, and Demo. MG has received speaker fees and conference travel grants from pharmaceutical companies, including AstraZeneca, GSK, Elpen, Boehringer Ingelheim, Novartis, Pfizer, UCB, Chiesi, Menarini, Roche, MSD, and Sherhing-Plough. MG has also received payment for consulting and advisory board involvement from AstraZeneca, GSK, Novartis, and Boehringer Ingelheim. The authors report no other conflicts of interest in this work.

\section{References}

1. Bahadori K, Doyle-Waters MM, Marra C, et al. Economic burden of asthma: a systematic review. BMC Pulm Med. 2009;9:24.

2. Braman SS. The global burden of asthma. Chest. 2006;130(1 suppl): $4 \mathrm{~S}-12 \mathrm{~S}$

3. Manson A. Language concordance as a determinant of patient compliance and emergency room use in patients with asthma. Med Care. 1988; 26(12):1119-1128.

4. Ginasthma [homepage on the Internet]. From the Global Strategy for Asthma Management and Prevention, Global Initiative for Asthma (GINA) 2011. Available from: http://www.ginasthma.org/. Accessed July 8, 2016.

5. Goldcopd [homepage on the Internet]. From the Global Strategy for the Diagnosis, Management and Prevention of COPD, Global Initiative for Chronic Obstructive Lung Disease (GOLD) 2011. Available from: http:// www.goldcopd.org/. Accessed July 8, 2016.

6. Cerveri I, Locatelli F, Zoia MC, Corsico A, Accordini S, de Marco R. International variations in asthma treatment compliance: the results of the European Community Respiratory Health Survey (ECRHS). Eur Respir J. 1999;14(2):288-294.

7. Charles MS, Blanchette CM, Silver H, Lavallee D, Dalal AA, Mapel D. Adherence to controller therapy for chronic obstructive pulmonary disease: a review. Curr Med Res Opin. 2010;26(10):2421-2429.

8. Dolovich MB, Ahrens RC, Hess DR, et al; American College of Chest Physicians; American College of Asthma, Allergy, and Immunology. Device selection and outcomes of aerosol therapy: evidence-based guidelines: American college of chest physicians/American college of asthma, allergy, and immunology. Chest. 2005;127(1):335-371. 
9. Anderson P. Patient preference for and satisfaction with inhaler devices. Eur Respir Rev. 2005;14:109-116.

10. Chrystyn H, Small M, Milligan G, Higgins V, Gil EG, Estruch J. Impact of patients' satisfaction with their inhalers on treatment compliance and health status in COPD. Respir Med. 2014;108(2):358-365.

11. Small M, Anderson P, Vickers A, Kay S, Fermer S. Importance of inhaler-device satisfaction in asthma treatment: real-world observations of physician-observed compliance and clinical/patient-reported outcomes. Adv Ther. 2011;28(3):202-212.

12. Restrepo RD, Alvarez MT, Wittnebel LD, et al. Medication adherence issues in patients treated for COPD. Int J Chron Obstruct Pulmon Dis. 2008;3(3):371-384.

13. Ware JE Jr, Davies-Avery A, Stewart AL. The measurement and meaning of patient satisfaction. Health Med Care Serv Rev. 1978;1(1): $3-15$.

14. Markson LE, Vollmer WM, Fitterman L, et al. Insight into patient dissatisfaction with asthma treatment. Arch Intern Med. 2001;161(3): 379-384.

15. Darba J, Ramirez G, Sicras A, Francoli P, Torvinen S, Sanchez-de la Rosa R. The importance of inhaler devices: the choice of inhaler device may lead to suboptimal adherence in COPD patients. Int J Chron Obstruct Pulmon Dis. 2015;10:2335-2345.

16. Grekas N, Athanassiou A, Iskos C, Panagiotakos D, Papataxiarchou A, Porichi O. Reliability of the FSI-10 questionnaire for the assessment of the usability of drug inhalers in Greek patients. Arch Hellen Med. 2011; 28:257-260.

17. Perpina TM, Viejo JL, Sanchis J, et al. [Assessment of patient satisfaction and preferences with inhalers in asthma with the FSI-10 Questionnaire]. Arch Bronconeumol. 2008;44(7):346-352.

18. Laube BL, Janssens HM, de Jongh FH, et al; European Respiratory Society; International Society for Aerosols in Medicine. What the pulmonary specialist should know about the new inhalation therapies. Eur Respir J. 2011;37(6):1308-1331.

19. Molimard M, Colthorpe P. Inhaler devices for chronic obstructive pulmonary disease: insights from patients and healthcare practitioners. J Aerosol Med Pulm Drug Deliv. 2015;28(3):219-228.

20. Lareau SC, Yawn BP. Improving adherence with inhaler therapy in COPD. Int J Chron Obstruct Pulmon Dis. 2010;5:401-406.

21. Schulte M, Osseiran K, Betz R, et al. Handling of and preferences for available dry powder inhaler systems by patients with asthma and COPD. J Aerosol Med Pulm Drug Deliv. 2008;21(4):321-328.

22. van der Palen J, van der Valk P, Goosens M, Groothuis-Oudshoorn K, Brusse-Keizer M. A randomised cross-over trial investigating the ease of use and preference of two dry powder inhalers in patients with asthma or chronic obstructive pulmonary disease. Expert Opin Drug Deliv. 2013;10(9):1171-1178.

23. Voshaar T, Spinola M, Linnane P, et al. Comparing usability of NEXThaler ${ }^{\circledR}$ with other inhaled corticosteroid/long-acting $\beta_{2}$-agonist fixed combination dry powder inhalers in asthma patients. $J$ Aerosol Med Pulm Drug Deliv. 2014;27(5):363-370.
24. Miravitlles M, Montero-Caballero J, Richard F, et al. A cross-sectional study to assess inhalation device handling and patient satisfaction in COPD. Int J Chron Obstruct Pulmon Dis. 2016;11:407-415.

25. Ozturk C, Kaya A, Bilgin C, et al. Evaluation of inhaler technique and patient satisfaction with fixed-combination budesonide/formoterol dry-powder inhaler in chronic obstructive pulmonary disease (COPD): data on real-life clinical practice in Turkey. Tuberk Toraks. 2012;60(4): 301-313.

26. Serra-Batlles J, Plaza V, Badiola C, Morejon E; Inhalation Devices Study Group. Patient perception and acceptability of multidose dry powder inhalers: a randomized crossover comparison of Diskus/ Accuhaler with Turbuhaler. J Aerosol Med. 2002;15(1):59-64.

27. van der Palen J, Klein JJ, Schildkamp AM. Comparison of a new multidose powder inhaler (Diskus/Accuhaler) and the Turbuhaler regarding preference and ease of use. J Asthma. 1998;35(2):147-152.

28. Gioulekas D, Papakosta D, Vordoyianni P, Baloti H, Vamvalis C. A comparison of the clinical efficacy and patient acceptability of terbutaline Turbuhaler and salbutamol Rotahaler, in adult patients with asthma. Respir Med. 1996;90(4):205-209.

29. Kozma CM, Slaton TL, Monz BU, Hodder R, Reese PR. Development and validation of a patient satisfaction and preference questionnaire for inhalation devices. Treat Respir Med. 2005;4(1):41-52.

30. Atkinson MJ, Sinha A, Hass SL, et al. Validation of a general measure of treatment satisfaction, the Treatment Satisfaction Questionnaire for Medication (TSQM), using a national panel study of chronic disease. Health Qual Life Outcomes. 2004;2:12.

31. Shikiar R, Rentz AM. Satisfaction with medication: an overview of conceptual, methodologic, and regulatory issues. Value Health. 2004; $7(2): 204-215$.

32. Grekas N, Athanassiou K, Papataxiarchou K, Rizea SS, Silvestro L. Pharmacokinetic study for the establishment of bioequivalence of two inhalation treatments containing budesonide plus formoterol. J Pharm Pharmacol. 2014;66(12):1677-1685.

33. Soulele K, Macheras P, Silvestro L, Rizea SS, Karalis V. Population pharmacokinetics of fluticasone propionate/salmeterol using two different dry powder inhalers. Eur J Pharm Sci. 2015;80:33-42.

34. Macheras P. Comment and reply on: a randomized crossover trial investigating the ease of use and preference of two dry powder inhalers in patients with asthma of chronic obstructive pulmonary disease. Expert Opin Drug Deliv. 2014;11(5):823-824.

35. Ninane V, Vandevoorde J, Cataldo D, et al. New developments in inhaler devices within pharmaceutical companies: a systematic review of the impact on clinical outcomes and patient preferences. Respir Med. 2015; 109(11):1430-1438. 


\section{Supplementary material}

The Feeling of Satisfaction with Inhaler (FSI- 10 questionnaire)

How would you score the inhalation device you have used in the last week on the following points? Choose only I response, the one that best reflects your opinion. There are no right or wrong answers. We simply want to know your opinion on certain features of the inhaler.

Please answer honestly and do not leave any questions unanswered.

I. Has it been easy to learn how to use the inhaler?
$\square$ Very
$\square$ Fairly
$\square$ Somewhat
$\square$ Not very
$\square$ Hardly at all

2. Was it easy to prepare the inhaler for use?

$\begin{array}{llll}\square \text { Very } & \square \text { Fairly } & \square \text { Nomewhat very }\end{array}$

3. Was it easy to use the inhaler?
$\square$ Very
$\square$ Fairly
$\square$ Somewhat
$\square$ Not very
$\square$ Hardly at all

4. Was it easy to keep the inhaler clean and in good working condition?
$\square$ Very
$\square$ Fairly
$\square$ Somewhat
$\square$ Not very
$\square$ Hardly at all

5. Was it easy to continue normal activities with the use of the inhaler?
$\square$ Very
$\square$ Fairly
$\square$ Somewhat
$\square$ Not very
$\square$ Hardly at all

6. Did the inhaler fit your lips comfortably?
$\square$ Very
$\square$ Fairly
$\square$ Somewhat
$\square$ Not very
$\square$ Hardly at all

7. Was using the inhaler easy in terms of size and weight?
$\square$ Very
$\square$ Fairly
$\square$ Somewhat
$\square$ Not very
$\square$ Hardly at all

8. Was it easy to carry the inhaler with you?
$\square$ Very
$\square$ Fairly
$\square$ Somewhat
$\square$ Not very
$\square$ Hardly at all

9. After you've used the inhaler, do you have the feeling that you used it correctly?
$\square$ Very
$\square$ Fairly
$\square$ Somewhat
$\square$ Not very
$\square$ Hardly at all

10. Overall, considering your responses to the previous questions, were you satisfied with the inhaler?
$\square$ Very
$\square$ Fairly
$\square$ Somewhat
$\square$ Not very
$\square$ Hardly at all

\section{Publish your work in this journal}

The International Journal of COPD is an international, peer-reviewed journal of therapeutics and pharmacology focusing on concise rapid reporting of clinical studies and reviews in COPD. Special focus is given to the pathophysiological processes underlying the disease, intervention programs, patient focused education, and self management protocols
This journal is indexed on PubMed Central, MedLine and CAS. The manuscript management system is completely online and includes a very quick and fair peer-review system, which is all easy to use. Visit http://www.dovepress.com/testimonials.php to read real quotes from published authors.

Submit your manuscript here: http://www.dovepress.com/international-journal-of-chronic-obstructive-pulmonary-disease-journal 